\title{
Clinical, Neurodevelopmental and Etiological profile of children with Cerebral Palsy
}

\author{
Gedam DS ${ }^{1}$, Patel $\mathbf{U}^{2}$, Shrivastava $\mathbf{J}^{3}$, Patel $\mathbf{U}^{4}$, Ratre BK ${ }^{5}$ \\ ${ }^{1}$ Dr D Sharad Gedam*, Professor of Pediatrics, ${ }^{2}$ Dr Umesh Patel*, Associate Professor of Pediatrics, ${ }^{3}$ Dr Jyotsna Shrivastav, \\ Professor of Pediatrics, Gandhi Medical College, Bhopal, ${ }^{4}$ Dr Narmada Pate*1, Assistant Professor of Medicine, ${ }^{5}$ Dr \\ Bhupendra Kumar Ratre*, Associate Professor of Internal Medicine. *Affiliated with L N Medical College, Bhopal, India.
}

Address for correspondence: Dr D Sharad Gedam, Email: sharad.gedam@gmail.com

\begin{abstract}
Background: Clinical spectrum of cerebral palsy (CP) is different in developing and developed countries. We evaluated the clinical profile, etiological factors and co-morbidities of children with CP in central India. Methods: 50 children with CP came to the hospital in our rehabilitation center were compared with our previous study done in India and western countries. Results: Spastic quadriplegia is the commonest type of CP (90\%). Birth asphyxia remains the main (48\%) etiological factor. Prematurity was second most common (22\%), Pre-eclamsia (10\%), convulsions (10\%), infection (8\%) and pathological jaundice $(8 \%)$ other important etiological factors. due to bilirubin-encephalopathy remained same ( 30\%). Microcephaly $(56 \%)$, Speech problems (34\%), seizures (36\%), auditory defect $(8 \%)$ and visual defect $(4 \%)$ are common co-morbidities. Common neuroimaging findings include cortical atrophy (50\%), periventricular leukomalacia (12.5\%) and developmental defect (12.5\%). Conclusion: The spectrum of $\mathrm{CP}$ is evolving in the developing countries. Lack of proper antenatal and perinatal care, malnutrition and infections appeared to be the major factors for development of $\mathrm{CP}$.
\end{abstract}

Keywords: Asphyxia, Cerebral palsy, Spastic, Quadriplegia, Seizures

\section{Introduction}

Cerebral palsy (CP) is a common developmental disability first described by William Little in the 1840s. It is one of the three most common life long developmental disabilities ( other two being autism and mental retardation) causing considerable burden to affected individuals and their families due to lifelong disability[1]. The condition poses considerable diagnostic and therapeutic challenges to the pediatrician and pediatric neurologist with variable degree of involvement ranging from minimal disability to total dependent of bed ridden severe form.

Cerebral palsy is primarily a disorder of movement and posture. It is defined as an "umbrella term covering a group of non-progressive, but often changing, motor impairment syndromes secondary to lesions or anomalies of the brain arising in the early stages of its development".[2] Cerebral palsy happens when the areas of the brain that control movement and posture do not develop correctly or get damaged. It is often associated with epilepsy and abnormality of speech, vision intellect. It is a static encephalopathy in which, even though the primary lesion, anomaly or injury is static, the clinical

Manuscript received: $15^{\text {th }}$ Apr 2014

Reviewed: $16^{\text {th }}$ Apr 2014

Author Corrected; $29^{\text {th }}$ Apr 2014

Accepted for Publication: $10^{\text {th }}$ May 2014 pattern of presentation may change with time due to growth and developmental plasticity and maturation of the central nervous system.

Cerebral Palsy is a common problem; the worldwide incidence is estimated between 2 to 2.5 per 1000 live births [3]. Despite recent advances in neonatal management and obstetric care incidence and severity of $\mathrm{CP}$ is increasing [4]. This is because of more and more survival of premature, very low birth weight and severe birth asphyxiated babies. The incidence in premature babies is much higher than in term babies. For the vast majority of term infants who develop $\mathrm{CP}$, birth asphyxia or obstetric complications cannot be ascribed as the cause $[5,6]$.

Recent clinical research in cerebral palsy has focused on the identification of prenatal or perinatal risk factors [7]. Despite these efforts, uncertainty continues to exist regarding the spectrum of etiologies and their relative contribution. Advance in technology and their appropriate use in clinical practice have certainly increased the identification of possible cause and reduced the percentage of cerebral palsy of unknown cause. Knowledge of the causes of cerebral palsy, including their distribution and relative frequency, have significant 


\section{Research Article}

implications for ongoing efforts directed at intervention and prevention strategies.

We have conducted this study to find out possible and probable etiological factors in our scenario \& to have better understanding of modes of clinical presentation. We have also assessed developmental profile of these children.

\section{Material and Methods}

The present study was hospital based study comprising 50 patient of cerebral palsy between 6 months to 8 years of age. Patient were selected randomly who were came to attend high risk clinic in department of pediatrics, Gandhi Medical College and Composite regional centre for persons with disability, Bhopal (MP), without any bias for sex.

Exclusion Criteria-
1. Progressive neurological disorder

2. Malnutrition grade IV

3. Clinically significant systemic illness (Any systemic illness more than 1 month duration)

Each child was subjected to complete medical and neurological examination to detect cases with $\mathrm{CP}$. These diseased children were subjected to meticulous neurological and medical assessment, brain MRI, EEG. A detailed history including antenatal, perinatal, postnatal, developmental history and obstetrical history of mothers especially birth asphyxia and prolong labour were taken. Present illness and past significant history related with disabilities were taken.

Clinical examination with particular emphasis on neurological examination was done. Findings were recorded on restructured proforma with special emphasis on developmental profile and developmental quotient. Necessary investigations were done in all patients.

\section{Results}

50 children of cerebral palsy between 6 months to 8 years of age were included in this study.

Table No 1: Age and Sex distribution of Patients

\begin{tabular}{|c|c|c|c|c|c|c|}
\hline \multirow{3}{*}{ Age group } & \multirow{3}{*}{ No of cases } & \multirow{3}{*}{$\%$} & \multicolumn{4}{|c|}{ Gender } \\
\hline & & & \multicolumn{2}{|c|}{ Male } & \multicolumn{2}{|c|}{ Female } \\
\hline & & & No & $\%$ & No & $\%$ \\
\hline 6 Months- 1 Year & 03 & 06 & 02 & 04 & 01 & 02 \\
\hline 1 Year- 5 Years & 34 & 68 & 24 & 48 & 07 & 14 \\
\hline 5 Years-8 Years & 13 & 26 & 12 & 24 & 04 & 08 \\
\hline Total & 50 & 100 & 38 & 76 & 12 & 24 \\
\hline
\end{tabular}

This table shows that maximum number of patients $(68 \%)$ was in the age group of 1-5 years and minimum numbers of patients $(6 \%)$ were in the age group of 5-8 years. Male to female child ratio was $3: 1$.

Table No 2: Gestational maturity of patients $(n=50)$

\begin{tabular}{|l|l|l|l|l|}
\hline Maturity & Male & Female & Total & Percentage \\
\hline Pre-term & 10 & 01 & 11 & 22 \\
\hline Term & 25 & 12 & 37 & 74 \\
\hline Post-term & 02 & 00 & 02 & 04 \\
\hline Total & 37 & 13 & 02 & 100 \\
\hline
\end{tabular}

Table No-02 depicts that majority of patients were term born children (74\%). $22 \%$ children were born premature.

Table No 3: Maternal age and Birth Order in affected children

\begin{tabular}{|l|l|l|l|l|l|}
\hline \multicolumn{2}{|c|}{ Maternal Age } & \multicolumn{2}{c|}{ Birth Order } \\
\hline Age group & No. of cases & $\%$ & Order of Birth & No. of cases & $\%$ \\
\hline$<20$ Years & 07 & 14 & $1^{\text {st }}$ & 18 & 36 \\
\hline $20-30$ Years & 37 & 74 & $2^{\text {nd }}-3^{\text {rd }}$ & 19 & 38 \\
\hline$>30$ Years & 06 & 12 & $4^{\text {th }}-5^{\text {th }}$ & 07 & 14 \\
\hline Total & 100 & $\geq 6^{\text {th }}$ & 06 & 12 \\
\cline { 3 - 6 } & \multirow{2}{*}{} & Total & 50 & 100 \\
\hline
\end{tabular}


This table shows that in $74 \%$ cases maternal age at the time of birth of child was between $20-30$ years. In $14 \%$ cases maternal age was less than 20 years and in $12 \%$ cases it was more than 30 years. In our study $36 \%$ of affected children were found in first birth order and $38 \%$ in $2^{\text {nd }} / 3^{\text {rd }}$ birth order.

Table No 4: Presenting symptoms and associated defects

\begin{tabular}{|c|c|c|c|c|c|c|}
\hline \multirow{2}{*}{$\begin{array}{l}\text { S. } \\
\text { No. }\end{array}$} & \multicolumn{3}{|l|}{ Symptoms } & \multicolumn{3}{|c|}{ Associate defects } \\
\hline & Name & No. of cases & $\%$ & Name & No. of cases & $\%$ \\
\hline 01 & Delayed milestone & 49 & 98 & Microcephaly & 28 & 56 \\
\hline 02 & $\begin{array}{l}\text { Feeding difficulties } \& \\
\text { drooling of saliva }\end{array}$ & 19 & 38 & Convulsion & 18 & 36 \\
\hline 03 & Convulsion & 18 & 36 & Speech defect & 17 & 34 \\
\hline 04 & Speech defects & 17 & 34 & Auditory defect & 04 & 08 \\
\hline \multirow[t]{3}{*}{05} & $\begin{array}{l}\text { Distribution of tone \& } \\
\text { posture- }\end{array}$ & & & \multirow[t]{3}{*}{ Visual defect } & \multirow[t]{3}{*}{02} & \multirow[t]{3}{*}{04} \\
\hline & 1. Stiffness & 04 & 08 & & & \\
\hline & 2. Limpness & 01 & 02 & & & \\
\hline
\end{tabular}

Above table shows that delayed milestone is most common presenting symptoms in $98 \%$ cases, followed by feeding difficulty, convulsion and speech defect in $38 \%, 36 \%$ and $34 \%$ cases. Similar microcephaly is commonest associate defect in $56 \%$ cases.

Table No 5: Probable Etiological Factors

\begin{tabular}{|c|c|c|c|c|c|}
\hline Etiological factors & No of cases & Percentage & & No & $\%$ \\
\hline \multirow[t]{2}{*}{ Antenatal } & \multirow[t]{2}{*}{08} & \multirow[t]{2}{*}{16} & 1.Pre-eclamsia & 05 & 10 \\
\hline & & & 2.Antipartum Hemorrhage & 03 & 06 \\
\hline \multirow[t]{3}{*}{ Perinatal } & \multirow[t]{3}{*}{24} & \multirow[t]{3}{*}{48} & 1.Birth Asphyxia & 24 & 48 \\
\hline & & & $\begin{array}{l}\text { 2.Abnormal Labour- } \\
\text { a. Prolong Labour } \\
\text { b. Forceps delivery } \\
\text { c. Cesarean Section }\end{array}$ & $\begin{array}{l}01 \\
01 \\
02 \\
\end{array}$ & $\begin{array}{l}02 \\
02 \\
04\end{array}$ \\
\hline & & & 3.Prematurity & 11 & 22 \\
\hline \multirow[t]{3}{*}{ Postnatal } & \multirow[t]{3}{*}{09} & \multirow[t]{3}{*}{18} & 1.Infection & 04 & 08 \\
\hline & & & 2.Convulsion & 05 & 10 \\
\hline & & & 3.Pathological Jaundice & 04 & 08 \\
\hline Mixed & 02 & 04 & & & \\
\hline Unknown & 07 & 14 & & & \\
\hline Total & 50 & 100 & & & \\
\hline
\end{tabular}

Table No 05 shows that perinatal insult were the most common cause of cerebral palsy in $48 \%$ cases. In $14 \%$ cases despite using best possible diagnostic modalities, cause remains unknown. Birth asphyxia was the commonest cause ( $48 \%$ ) of cerebral palsy. In $22 \%$ cases prematurity was culprit.

Table No 6: Clinical and Topographic presentation of Cerebral Palsy

\begin{tabular}{|l|l|l|l|l|l|}
\hline Clinical Type & No of cases & $\mathbf{\%}$ & Topographic Type & No. of cases & \% \\
\hline Spastic & 45 & 90 & Quadriplegia & 23 & 46 \\
\hline Atonic & 04 & 08 & Diplegia & 19 & 38 \\
\hline Mixed & 01 & 02 & Hemiplegia & 08 & 16 \\
\hline Total & 50 & & 50 & 100 \\
\hline
\end{tabular}

Table No 06 shows that spastic type was the most common (90\%) type of cerebral palsy, followed by atonic or hypotonic with $08 \%$ prevalence. There was no case of athetosis in our study. In topographic distribution quadriplegia was the 
commonest type (46\%) followed by diplegic type (19\%). There was no case of monoplegia, paraplegia, triplegia or double hemiplegia in the study.

Table No 7: Neuroimaging and EEG finding in Cerebral Palsy

\begin{tabular}{|l|l|l|l|l|l|}
\hline \multicolumn{2}{|c|}{ Neuroimaging findings } & \multicolumn{3}{c|}{ EEG Pattern } \\
\hline \multicolumn{1}{|c|}{ Findings } & No. of cases & $\%$ & Total EEG done & Abnormal EEG & Normal EEG \\
\hline Cortical atrophy & 12 & 50 & 18 & 15 & 03 \\
\hline Maldevelopment & 03 & 12.5 & & & \\
\hline $\begin{array}{l}\text { Periventricular } \\
\text { Leucomalacia }\end{array}$ & 03 & 12.5 & & & \\
\hline Basal ganglia lesion & 00 & 00 & & & \\
\hline Others findings & 01 & 04.17 & & & \\
\hline Normal findings & 08 & 33.33 & & & \\
\hline Total & 24 & 100 & & & \\
\hline
\end{tabular}

Table No 7 shows that total 24 patients were undergone radiological assessment. It was normal in 8 (33\%) of patients and abnormal in 16 (66\%). Most common radiological finding was cortical atrophy in 50\% cases, maldevelopment and periventricular leukomalacia were other common findings (12.5\% each). Nearly one third patients (33.34\%) there was normal neuroimaging. EEG was done in 18 cases, those having convulsions, out of them 15 patients having abnormal EEG findings.

\section{Discussion}

Cerebral palsy is the commonest cause of physical and mental disability in children. Despite huge research work that done in this field, yet in many case cause remains unknown. In birth cohorts from developed countries, the prevalence is 1-2/1000 live births. The prevalence rises dramatically with decreasing gestational age at birth such that among extremely low gestational age newborns. In gestational age $<28$ weeks, the prevalence is about 100 per 1000 of surviving infant, a 100-fold higher risk than infants born at term. As a function of all live births, the prevalence has been remarkably stable for decades, but this has not been the case among very low birth weight and very preterm infants, among whom prevalence

increased after the introduction of neonatal intensive care and has begun to decrease in the past decade [1]. This study aimed at highlighting some of the major clinical presentation and etiological risk factors, which is an essential first step in reducing the burden of this disease in our country.

In our study $68 \%$ patients belong to $1-5$ years of age group, because in this age group developmental retardation and physical disability become more and more obvious and child is brought to the hospital by worried parents. In less than 1 year of age, features of cerebral palsy are not very obvious and only can be identify by qualified and experienced pediatrician. By age of 8 years parents understand the nature of disease very well and become reluctant to come to the hospital. This is the reason why less than 1 year and more than 8 years children were less in numbers in hospital. Regular checkup of child can bring down the age of presentation, as age of presentation is very important for a spastic child, because early intervention can lead to better outcome in terms of quality of life. So health care workers should trained for early reorganization of sign of developmental delay.

There was a male preponderance in our study with male: female ratio 3.16:1. Cerebral palsy (CP) and related developmental disorders are more common in males than in females, but the reasons for this disparity are uncertain. This can be simple byproduct of our social practice where any health related problem of male child is given more concern by parents, while females are ignored till last. Males born very preterm also appear to be more vulnerable to white matter injury and intraventricular hemorrhage than females [8]. Experimental studies in adult animals and data from adult patients with stroke indicate that sex hormones such as estrogens provide protection against hypoxic-ischemic injury, and the neonatal brain is also influenced by these hormones [9]. However, hormonal influences on the fetus and neonates are substantially different from those on adults. Recent data from neonatal rodents subjected to hypoxia-ischemia also demonstrate differences between males and females [10].

Our study shows that gestation age has profound effect on risk of cerebral palsy. Though cerebral palsy developed in all gestational patients but majority of patients (74\%) belong to term category. These results are just opposite to 


\section{Research Article}

mentioned in literatures. Neonate survivors born before week 33 are up to 30 times more likely to risk of cerebral palsy than a baby born at term.[11] Most of diaplegic cerebral palsy developed in preterm babies. Recent research indicate that there is decrease incidence of cerebral palsy after 2000, which is due to improve perinatal care [12]. But prematurity represents one of the risk factors of newborns' mortality, morbidity and derangements of long-term neurological development especially cerebral palsy and mental retardation. With the increase of number of preterm newborns, problems with subsequent neurological development have also increased [13].

In present study $74 \%$ mothers delivered the affected child at the age between 20-30 years. It is insignificant because this is the age of highest fertility where most of parents complete their family. NA Fletcher et al also observed in his study that there is no effect of parental age or birth in spastic quadriplegia or diplegia, but a paternal age effect was detected in those with athetoid / dystonic cerebral palsy and congenital hemiplegia [14]. Maternal age $>35$ years is a important risk factor for cerebral palsy [15]. Multiple pregnancy, medicine used in early pregnancy, harmful environment and recurrent vaginal bleeding during pregnancy are other important risk factors of cerebral palsy [15]. Father under 20 years, first child or fifth (or more) child and baby of low birth weight (less than 2.5 pounds) can increase chance of cerebral palsy.

In present study delay milestone was the commonest presenting symptoms in $98 \%$ cases. Feeding difficulty, drooling of saliva, convulsion and speech defect were the other common symptoms, for which child brought to the hospital. Not all signs are visible at the time of birth or after few months of birth. In infants low muscle tone (baby feels 'floppy' when picked up), unable to hold up its own head while lying on their stomach or in a supported sitting position, muscle spasms or feeling stiff, poor muscle control, reflexes and posture, delayed development (can't sit up or independently roll over by 6 months), and preference to use one side of their body are very important early sing of cerebral palsy. Cerebral palsy is a complex disability and diagnosis is not always an easy process. Doctors may suspect cerebral palsy if a baby has slow motor development, has tight or floppy muscle tone, or displays unusual postures. The 'General Movements Assessment' can be conducted from birth until 3 months of age. It has been shown to be a strong predictor of cerebral palsy, particularly when certain changes to the brain are seen on an MRI. However, it cannot predict the severity of cerebral palsy.
The distribution of etiological factors according to period of their operation shows that antenatal factors were involved in $16 \%$ cases, perinatal in $48 \%$ cases and postnatal in $18 \%$ cases. Efforts linking CP to specific etiological factors have been attempted worldwide [1618]. Risk factors identified in this study are more or less similar to the ones reported by others. In about a half of the children (48\%) birth asphyxia was most common causative factor, followed by prematurity in $22 \%$ cases. Pre-eclampsia $(10 \%)$, infection $(8 \%)$, convulsions $(10 \%)$ and pathological jaundice $(8 \%)$ are other important factors. Many etiological factors were overleaping and many patients having more than one etiological factors. Among all these factors, the presence of infection or fever during pregnancy was more prominent in the poor-resource community. National Institutes of Health Collaborative Perinatal Project (NCPP) also revealed that moderate to severe inflammatory infiltrates present within the placenta increase the risk of developing $\mathrm{CP}$ in both preterm and term infants $[19,20]$. Significant association between preterm and CP has been seen in various Western studies [21]. This is mainly because of the increased survival of preterm and low birth weight babies due to the availability of advanced obstetric and neonatal care, which indirectly increases the risk of $\mathrm{CP}$ in these infants. However, unlike Western figures, most $\mathrm{CP}$ children examined in this particular study were born at term. Lack of antenatal care specially in underdeveloped and developing counties, put mother and unborn child to many antenatal, natal and postnatal complication and thereby increasing risk of cerebral palsy. There is a contradictory result of birth asphyxia as a causative agent of CP throughout literature. Western studies show that there is no significant association, while the developing countries especially North India, Nigeria and Malta found a strongly suggestive history of birth asphyxia in the affected children [22]. Observations supporting asphyxia as a contributory factor were also seen in this poor resource community. Acquired causes of $\mathrm{CP}$, like kernicterus, meningoencephalitis and neonatal seizures, greatly contributed to a significant portion of cerebral palsy. Post natal infections and neonatal seizures however, continue to be a strong cause of CP throughout the world [23, 24].

In our study spastic type of cerebral palsy was most common accounting for $90 \%$ of total cases. Quadriplegic (46\%) and diplegic (38\%) are important topographic type of $\mathrm{CP}$. This finding was consistent with other study result [25]. However, there are discrepancies between the developed and developing countries when it comes to identifying the commonest subtype of spastic CP. The spectrum of $\mathrm{CP}$ is evolving in the developing countries with an increase in diplegic and a decrease in quadriplegic $\mathrm{CP}$. The quadriplegic $\mathrm{CP}$ rates have been reported to be much higher in poor-resource countries as compared to 


\section{Research Article}

the developed countries [24]. The proposed reason for this decrease in quadriplaegic type of $\mathrm{CP}$ in developed countries is due to the increased survival of extremely premature infants [24]. Consanguineous marriage and lack of antenatal care were important community-related risk factors identified for spastic $\mathrm{CP}$ in some studies

Only few reports exist on neuroimaging abnormalities in children with cerebral palsy (CP) from India. In this study out of 50 patients 24 patients had undergone neuroimaging study. Neuroimaging abnormalities were seen in $66 \%$ of children, which is not comparable to other western studies that have reported incidence of 86 to $91 \%$ [27- 29]. The neurological abnormalities in the present study were different compared to those of a systematic review by Krageloh-Mann et al. [27], which included 14 studies and 388 children. The incidence of various abnormalities in the present study vs. that of KragelohMann et al. are malformations (12.5\% vs. 9\%), periventricular changes $(12.5 \%$ vs. $56 \%)$. Due to lesser number of preterm $(n=11 \& 22 \%)$ in our study incidence of periventricular changes was less. Malformations presenting as $\mathrm{CP}$ may have different management treatment, bearing on subsequent pregnancies and thus may require genetic counseling, and have medicolegal importance to obstetricians and neonatologists. Hence, the emphasis is on neuroimaging in children with clinically diagnosed CP. As pathogenic events affecting the developing brain can cause abnormalities depending on the stage of brain development, MRI has high potential to elucidate type, extent, and possible time of brain damage in children with CP. Further studies are needed to confirm the same in Indian children [26].

In our study EEG was done in 18 cases. EEG was positive in $83.3 \%$ cases. Senbin N et al (2002) also found abnormal EEG in $90.3 \%$ cases. Tetraplegic CP has higher incidence of epilepsy. Focal epileptiform activity, generalized slowing, and multifocal epileptiform activity were significantly frequent in epileptic CP [30].

Limitation of our study

There were several limitations to our study.

- The study only included a single block of the community who were came hospital for evaluation and not the whole community.

- Due to the nature of the research, lack of funds and manpower, a door-to-door survey was not conducted, which could have helped us identify further cases.

- Small sample size makes it difficult for us to accurately derive any true associations between the observed risk factors and CP.
- Genetic and metabolic investigations not done due to lack of fund and facilities.

Despite the limitations, it paves way for further studies that need to be conducted in this population on a larger scale to better assess and understand the various contributory components leading to the development of $\mathrm{CP}$. That will facilitate the process of developing effective preventive and rehabilitation strategies.

\section{Conclusion}

Spastic cerebral palsy is most common form of disease. Lack of proper antenatal care, delivery in a non-hospital setting and immediate neonatal care, malnutrition and infections appeared to be the major factors contributing towards the development of CP. Enhancing parents' knowledge and awareness about their initially un-born and later born child's condition as well as targeting the preventable causes could be crucial in modifying the trend cerebral palsy. Majority of parents are not able to continue therapy due to lack of treatment facilities, suggesting the dire need for setting up specific centers dedicated solely towards the management of this debilitating disease.

\section{Funding: Nil}

Conflict of interest: Nil

Permission from IRB: Yes

\section{References}

1. Sankar C, Mundkur N.Cerebral Palsy-Definition, Classification, Etiology and Early Diagnosis. Indian J Pediatr. 2005 Oct;72(10):865-8.

2. Mutch L, Alberman E, Hagberg B, Kodama K, Perat MV. Cerebral palsy epidemiology: where are we now and where are we going? Dev Med Child Neurol. 1992 Jun;34(6):547-51.

3. Rosen MG, Dickinson JC. The incidence of cerebral palsy. Am J Obstet Gynecol. 1992 Aug;167(2):417-23.

4. Nelson K.B. Can we prevent cerebral palsy? $N$ Engl J Med. 2003 Oct 30;349(18):1765-9.

5. Kuban KC, Leviton A. Cerebral Palsy. $N$ Engl J Med. 1994 Jan 20;330(3):188-95.

6. MacLennan A. A template for defining a causal relation between acute intrapartum events and cerebral palsy:international consensus statement. BMJ 1999 Oct;319(7219): 1054-9. 


\section{Research Article}

7. Torfs CP, van den Berg B, Oechsli FW, Communis S. Prenatal and perinatal factors in the etiology of cerebral palsy. J Pediatr. 1990 Apr;116(4):615-9.

8. Tioseco JA, Aly H, Essers J, Patel K, El-Mohandes AA. Male sex and intraventricular hemorrhage. Pediatr Crit Care Med.2006 Jan;7(1): 40-4.

9. Mage DT, Donner M. Female resistance to hypoxia: does it explain the sex difference in mortality rates? $J$ Womens Health (Larchmt) .2007 July-Aug. 15(6): 78694.

10. Johnston MV, Hagberg H. Sex and the pathogenesis of cerebral palsy. Dev Med child Neurol.2007 Jan;49(1):74-8.

11. Miller, Freeman \& Bachrach, Steven J. Cerebral Palsy: A Complete Guide for Caregiving. 1995. The John Hopkins University Press.

12. van Haastert IC, Groenendaal F, Uiterwaal CS, Termote JU, van der Heide-Jalving M, Eijsermans MJ, Gorter JW, Helders PJ, Jongmans MJ, de Vries LS. Decreasing incidence and severity of cerebral palsy in prematurely born children. J Pediatr. 2011 Jul;159(1):8691.

13. Kipiani T, Tatishvili N, Sirbiladze Ts. Long-term neurological development of the preterm newborns. Georgian Med News. 2007 Jan;(142):42-5.

14. N A Fletcher, J Foley. Parental age, genetic mutation, and cerebral palsy. J Med Genet. Jan 1993; 30(1): 44-46.

15. Xue J, Chen LZ, Xue L, Zhou Q. Meta-analysis of risk factors for childhood cerebral palsy during pregnancy. Zhongguo Dang Dai Er Ke Za Zhi. 2013 Jul;15(7):535-40.

16. Nazir B, Butt A, Shamoon M, Sheikh S, Malik M, Hashmat N. Etiology and Types of Cerebral palsy. Pak Paed J. 2003 Dec;27:152-6.

17. Reddihough DS, Collins KJ. The epidemiology and causes of cerebral palsy. Aust J Physiother. 2003; 49(1):712.

18. Singhi PD, Ray M, Suri G. Clinical spectrum of cerebral palsy in North India - an analysis of 1000 cases. J Trop Pediatr. 2002 Jun;48(3):162-6.
20. Stanley FJ, Blair E, Alberman E. Cerebral Palsies: Epidemiology and Causal Pathways. London: MacKeith Press. 2000; 8-13.

21. Clark SM, Ghulmiyyah LM, Hankins GD. Antenatal antecedents and the impact of obstetric care in the etiology of cerebral palsy. Clin Obstet Gynecol. 2008;51: $775-86$

22. Lagunju I, Okafor OO. An analysis of disorders seen at the Paediatric Neurology Clinic, University College Hospital, Ibadan, Nigeria. West Afr J Med. 2009; 28: 32832.

23. Belonwu RO, Gwarzo GD, Adeleke SI. Cerebral palsy in Kano, Nigeria - a review. Niger J Med. 2009 ApeJun; 18(2): 186-9.

24. Gladstone M. A review of the incidence and prevalence, types and aetiology of childhood cerebral palsy in resource-poor settings. Ann Tro Paediatr. 2010; 30(3): 181-96.

25. Krigger KW. Cerebral Palsy: an overview. Am Fam Physician. 2006 Jan 1;73(1): 91-100.

26. Aggrawal A, Mittal H, Debnath SKR, Rai A. Neuroimaging in Cerebral Palsy - Report from North India.Iran J Child Neurol. 2013 Autumn; 7(4): 41-6.

27. Krägeloh-Mann I, Horber V. The role of magnetic resonance imaging in elucidating the pathogenesis of cerebral palsy: a systematic review. Dev Med Child Neurol . 2007;49(2):144-51.

28. Korzeniewski SJ, Birbeck G, DeLano MC, Potchen MJ, Paneth N. A systematic review of neuroimaging for cerebral palsy. Journal of Child Neurology . 2008;23(2):216-27.

29. 12. Robinson MN, Peake LJ, Ditchfield MR, Reid SM. Magnetic Resonance imaging findings in population based cohort of children with cerebral palsy . Dev Med Child Neurol. 2009;51(1):39-45.

30. Senbil N, Sonel B, Aydin OF, Gürer YK.Epileptic and non-epileptic cerebral palsy: EEG and cranial imaging findings. Brain Dev. 2002 Apr;24(3):166-9. 


\section{How to cite this article?}

Gedam DS, Patel U, Shrivastava J, Patel U, Ratre BK. Clinical, Neurodevelopmental and Etiological profile of children with Cerebral Palsy. Pediatr Rev: Int J Pediatr Res 2014;1(1):17- 24. doi: 10.17511/ijpr.2014.i01.04 